\title{
Mapeamento SIG na Pesquisa e Inventário do Patrimônio Arqueológico de Guarulhos (PIPAG)
}

\author{
Luis Ferla* \\ Karina de Oliveira Oyakawa ** \\ Jaine Aparecida Diniz*** \\ Orlando Guarnier Cardin Farias ****
}

\begin{abstract}
FERLA, L.; OYAKAWA, K.O.; DINIZ, J.A.; FARIAS, O.G.C. Mapeamento SIG na
Pesquisa e Inventário do Patrimônio Arqueológico de Guarulhos (PIPAG). R. Museu

Arq. Etn., 26: 84-94, 2016.
\end{abstract}

Resumo: $\mathrm{O}$ mapeamento do patrimônio arqueológico levantado pelo Projeto Pipag se deu com o uso de geotecnologias digitais, mais especificamente por meio de um Sistema de Informação Geográfica (SIG). O artigo em questão tem o objetivo de discutir a metodologia utilizada para tal, mas não sem antes contextualizá-la a partir de uma abordagem mais geral sobre o impacto, os desafios e as oportunidades colocadas pela presença crescente dessas tecnologias no ofício do historiador. A experiência, assim relatada, concluiu o artigo, não apenas exemplifica a conveniência da tecnologia para a espacialização da pesquisa realizada no âmbito do Pipag, como enfatiza sua capacidade de fazê-la de forma amplamente sinérgica, ao permitir a devida articulação entre as diversas iniciativas e investigações envolvidas.

Palavras-chave: humanidades digitais; geotecnologias; SIG histórico; história de Guarulhos.

\section{Introdução}

$\mathrm{N}$ a descrição da metodologia do Projeto PIPAG, são discriminadas três etapas para a consecução do estudo: a pesquisa arqueológica; o inventário e mapeamento dos sítios arqueológicos identificados; e o ensino e a musealização do patrimônio arqueológico ${ }^{1}$. As atividades sob a responsabilidade dos autores desse

1 Plens, 2011: 10.

$\left.{ }^{*}\right)$ Historiador, Professor do Departamento de História da UNIFESP.

(**) Bolsista TT1/FAPESP do PIPAG, aluna de graduação de História da UNIFESP.

$\left({ }^{* * *}\right)$ Bolsista FAPESP do PIPAG, aluna de graduação de História da UNIFESP.

${ }^{(* * *)}$ Colaborador do PIPAG. relatório inserem-se na segunda etapa referida. Mais exatamente, dedicam-se à referenciação espacial do patrimônio arqueológico inventariado em um Sistema de Informação Geográfico (SIG) e a produção de mapas e visualizações a partir dele. Os SIGs constituem um ambiente computacional que permite a articulação de bancos de dados alfanuméricos com informações e visualizações espaciais. Na síntese de um estudioso do assunto, um SIG "é definido pela aquisição, armazenamento e análise de objetos e fenômenos dos quais a localização geográfica é uma característica importante ou crítica para a análise"2.

2 Tradução livre do original: "A GIS is designed for the collection, storage, and analysis of objects and phenomena where geographic location is an important characteristic or critical to the analysis" (Aronoff, 1995: 1). 


\section{O uso de SIG em história ${ }^{3}$}

A utilização dos recursos computacionais em análises espaciais já tem uma tradição bastante sólida, com um desenvolvimento bem mais acelerado a partir de meados dos anos noventa do século passado. O perfil exponencial da curva da difusão do SIG a partir de então pode ser considerado uma expressão particular das sucessivas revoluções tecnocientíficas que propiciaram as tecnologias digitais desde, pelo menos, meados dos anos 70 do século passado. De uma perspectiva mais específica, Stephen Hall associa a demanda pelo SIG a uma necessidade crescente de organização do fluxo avassalador de informações ${ }^{4}$, por sua vez, outra expressão característica daquelas transformações tecnológicas. Daí que as aplicações atuais dos SIGs cubram uma vastíssima gama de campos da atividade humana. A pesquisa histórica, no entanto, quase desconhece as possibilidades dessas tecnologias, apesar da pertinência dos estudos de fenômenos espaciais localizados no passado, e de suas transformações no decorrer do tempo, para o trabalho do historiador. A explicação para essa precariedade aparentemente paradoxal demanda uma análise algo mais detida, para além da conhecida e compreensível prevenção contra supostos renascimentos objetivistas e positivistas. Parte dela talvez esteja também na pequena tradição do uso das tecnologias da informação entre estudiosos das ciências humanas, em geral, e entre os historiadores, em particular, em contraposição ao que acontece em outras áreas, como nas ciências ditas naturais ou exatas. Por outro lado, e ainda em contraste com o mais frequente, a disponibilidade de dados espaciais em formato digital referentes a tempos passados é, evidentemente, muito menor do que acontece com o que se refere ao mundo atual. Tal fator se constitui, dessa forma, em causa e em consequência da pequena presença do

3 Para uma discussão mais abrangente sobre o uso de SIGs em investigações históricas, ver GREGORY; Ell, 2007.

4 Apud CHURCHILL, Robert; HILLIER, Amy. "Teaching with GIS”. In: Knowles, 2008: 66. geoprocessamento entre os historiadores. Esse relativo atraso é capaz, por sua vez, de restringir as possibilidades de financiamento, pois há que se levar em consideração o elevado custo que tradicionalmente costuma ser associado ao desenvolvimento de qualquer SIG - mormente de um SIG histórico -, no mais das vezes intensivo em utilização do tempo de recursos humanos e dispendioso em equipamentos e softwares. O perfil íngreme da curva de aprendizagem da tecnologia tampouco é um aspecto particularmente facilitador.

No entanto, a última década assistiu a um crescente interesse pelas tecnologias de SIG entre os historiadores, com o desenvolvimento de importantes iniciativas que já estão em condições de fornecer os contornos de um novo paradigma ${ }^{5}$. Inicialmente, deve se reconhecer um componente geracional na mudança de atitude frente ao "mundo digital". A impregnação da informática no cotidiano não apenas se aproxima da onipresença, como o faz cada vez mais desde o início da vida do indivíduo. Isso significa que os alunos de história de hoje estão muito mais familiarizados com "teclados, arquivos, conversões e downloads" do que os seus professores jamais estiveram, e do que os professores de seus professores jamais conceberam estar. Outra característica importante da tecnologia em questão, de impacto relevante na produção do conhecimento, é sua natureza sinérgica. Se, por um lado, sua utilização cotidiana implica em trabalho coletivo e não raro interdisciplinar, por outro seus resultados podem ser compartilhados e instrumentalizados de forma ampla e disseminada, por meio de sua disponibilização na rede mundial de computadores. Para além disso, no atual estágio tecnológico, não apenas os resultados atingidos, mas também os esforços isolados e parciais de iniciativas autônomas podem ser articulados e conjuminados, a partir das plataformas tecnológicas do SIG e da internet.

5 A bibliografia da área já conta com importantes coletâneas de trabalhos considerados referenciais. As primeiras a aparecer foram edições especiais das revistas Social Science History (v. 24: 3), no ano 2000, e History and Computing, v. 13, de 2001. De tempos mais recentes e, portanto, com trabalhos mais amadurecidos da área, é a obra Knowles, 2008. 
Além disso, o custo implicado no uso e desenvolvimento de SIGs vem decaindo dramaticamente, tanto no que diz respeito ao hardware como ao software. Os equipamentos associados ao desenvolvimento dos SIGs vêm se tornando crescentemente acessíveis, particularmente no que diz respeito ao armazenamento de dados. Uma boa ideia dessa evolução ocorrida na última década pode ser obtida pela análise de um projeto de SIG histórico apresentado em artigo de 2000, de autoria do pesquisador norte-americano Loren Siebert. ${ }^{6}$ Em 1993, o autor iniciava o trabalho de construção de um SIG dedicado à história da cidade de Tóquio dos 130 anos precedentes. Quando considerava os custos envolvidos em um projeto tão ambicioso e se referia especificamente aos softwares necessários, Siebert relatava ter encontrado opções relativamente viáveis, ainda que acabasse por não revelar os valores respectivos e fizesse a ressalva de que, para "projetos pequenos", o valor poderia ficar abaixo dos "mil dólares". ${ }^{7}$ Com relação ao espaço de armazenamento dos dados de seu projeto, correspondentes a "80 mapas escaneados, muitos planos de informações vetoriais, e muitas tabelas de dados associados, o tamanho atual da base de dados SIG da história espacial de Tóquio atinge cerca de um gigabyte" ${ }^{8}$ Hoje, o mesmo artigo teria que fazer menção à opção gratuita do software livre e à irrelevância do tamanho da massa de dados quando contrastada com a capacidade de diversos dispositivos de armazenamento facilmente acessíveis (dito de outro modo, 130 anos da história espacial de Tóquio caberiam hoje em um pen-drive dos mais simples).

Essas novas tendências têm estimulado a difusão do SIG entre os historiadores, e o presente projeto é mais uma dentre inúmeras expressões disso.

\section{A escolha do software de SIG}

A opção preferencial na escolha do software de SIG para o projeto procurou evitar as cha-

6 Siebert, 2000: 537-574.

7 Siebert, 2000: 544.

8 Siebert, 2000: 550 . madas alternativas proprietárias, que, por meio de seu alto custo e de suas várias restrições ao seu uso, modificação e reprodução, acabam por constranger a livre circulação do conhecimento. Os primeiros softwares livres da área surgiram na última década, com o marco inicial em 1999, quando o software GRASS, originalmente desenvolvido por uma instituição militar norte-americana (U.S. Army Corps of Engineers Construction Engineering Research Laboratory) passou a adotar a licença GPL (General Public License). ${ }^{9}$ Desde então, seu aprimoramento e sofisticação os têm colocado cada vez mais ao nível dos melhores softwares proprietários, tanto no que se refere às potencialidades de seus recursos, como ao caráter "amigável" de suas interfaces, com todas as vantagens inerentes à aquisição gratuita e à livre reprodução. Particularmente, para o caso da introdução de uma tecnologia relativamente desconhecida numa comunidade de pesquisadores e estudantes da área de ciências humanas, é bastante interessante e conveniente essa feliz combinação entre operacionalidade, facilidade de uso e livre acesso.

A partir dessas considerações, foi escolhido para uso no projeto o software gvSIG ${ }^{10}$, uma das mais difundidas opções de livre acesso e reprodução atualmente disponíveis. Pesou também nessa definição a existência de um outro projeto de SIG no Departamento de História da Unifesp que faz uso intensivo do gvSIG já há mais de três anos. ${ }^{11}$

\section{Equipe responsável}

A equipe responsável por essa parte do projeto Pipag foi constituída por Luis Ferla, pro-

9 Guest Editorial, 2004: 145-154 (http://www.informatik.

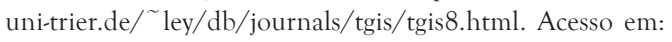
12 abr. 2015).

10 Mais informações em www.gvsig.org.

11 Tal projeto é desenvolvido pelo grupo Hímaco (História, Mapas e Computadores), constituído por alunos e professores da Unifesp e por técnicos e pesquisadores do Núcleo de Cartografia Histórica do Arquivo Público de São Paulo (www. unifesp.br/himaco). Os autores desse relatório são todos membros do grupo. 
fessor do Departamento de História da Unifesp; e por Karina de Oliveira Oyakawa, Jaíne Aparecida Diniz e Orlando Guarnier Cardin Farias, todos alunos de graduação daquele curso.

\section{Mapeamentos produzidos}

1 - Ruínas de Minas de Ouro;

2 - Registro de Terras;

3- Aforamentos de 1890 a 1950;

4 - Aforamentos década 1890;

5 - Aforamentos década 1900;

6 - Aforamentos década 1910;

7 - Aforamentos década 1920;

8 - Aforamentos década de 1940;

9 - Estradas e Caminhos antigos;

10 - Fábricas em Guarulhos de 1920 a 1970;

11 - Fábricas em Guarulhos década de 1920;

12 - Fábricas em Guarulhos década de 1930;

13 - Fábricas em Guarulhos década de 1940;

14 - Fábricas em Guarulhos década de 1950;

15 - Fábricas em Guarulhos década de 1960;

16 - Ruínas de Minas de Ouro e Igreja do Bonsucesso;

17 - Presença indígena por bairro;

18 - Terreiros de Umbanda e Candomblé.

19- Mapa do Inventário dos bens arqueológicos de Guarulhos;

Os mapas se encontram em: www2.unifesp.br/centros/arqueologia

\section{Metodologia}

Para exemplificar a metodologia utilizada na produção dos mapas do projeto, será apresentado aqui o protocolo de procedimentos adotado para elaborar os mapas da localização das indústrias. Ele corresponde, em linhas gerais, à metodologia adotada para toda a cartografia desenvolvida dentro do escopo do projeto. No caso específico do mapeamento das indústrias, foi fundamental a colaboração dos tutores e bolsistas do Programa de Educação Tutorial (PET), do Departamento de História da Unifesp ${ }^{12}$. No âmbito do PET, foi desenvolvida a pesquisa "Em torno da ferrovia e da rodovia: o processo de industrialização de Guarulhos e seu patrimônio industrial (1910 - 1960)". Seus resultados foram disponibilizados ao Projeto Pipag, consolidados em uma planilha eletrônica contendo informações referentes a 129 indústrias instaladas no Município de Guarulhos, de 1910 a 1970. A planilha continha os seguintes campos: "nome", "ano da fundação", "endereço", "situação atual”, e "uso original".

Com esses dados em mãos, os bolsistas do projeto procederam ao referenciamento geográfico das fábricas indicadas na planilha. Para isso, os endereços informados foram localizados em um site de mapeamento digital da internet (Google Mapas). ${ }^{13}$ Através da ativação do balão de latitude e longitude dos Labs do Google Maps, são identificadas as coordenadas de cada endereço. Como o sistema de projeção utilizado no Google Mapas (WGS 84, em graus decimais) não coincide com aquele mais adequado ao mapeamento da região da cidade de Guarulhos (SAD 69, 23S, em UTM), foi feita a conversão respectiva, com o uso do site Spacies Link ${ }^{14}$. À planilha original foram, portanto, acrescidos quatro novos campos: latitude (WGS84), longitude (WGS84), latitude (SAD69) e longitude (SAD69). Além disso, foi criado um campo de tipo numérico com a informação do ano da fundação de cada indústria. O campo "Ano de fundação", de tipo texto e de onde foi retirada a informação para o novo campo, foi assim renomeado para "data de fundação”. Essa operação teve o objetivo de permitir a criação de mapas temáticos no SIG que organizassem a informação de forma cronológica (figuras 4 a 10). Por fim, a planilha em Excel foi exportada para o formato csv (comma separeted values), compatível com o gvSIG ${ }^{15}$.

A importação dessa planilha para o software gvSIG permitiu a localização das fábricas em

12 Tutores: Edilene Teresinha Toledo, Marcia Eckert Miranda e Luis Filipe Silvério Lima; bolsistas: Alessandra Silva de Santana, Giorgia Burattini Saad Medeiros da Silva, Roger Camacho Barrero Junior, Silvani Silva Costa, Thomaz Barbeiro Gonçalves, Tuanny Folieni Antunes Lanzellotti e Wagner Pereira Silva.

13 http://maps.google.com.br/, acessado pela última vez em em 12 de abril de 2015.

14 Disponível em: http://splink.cria.org.br/conversor. Acesso em: 12 abr. 2015. 
coordenadas do mundo real (um aplicativo lê as coordenadas nos campos respectivos e os distribui espacialmente como vetores do tipo ponto). As visualizações produzidas, no entanto, só foram possíveis com a disponibilização de diversos planos de informação vetoriais referentes ao Município de Guarulhos, por parte da Secretaria do Meio Ambiente daquela cidade ${ }^{16}$, o que permitiu a composição da localização das fábricas com outras feições geográficas e urbanas da região ${ }^{17}$.

\section{Visualizações produzidas no SIG}

As figuras 1 a 11 indicam algumas visualizações produzidas no ambiente do SIG do projeto, todas referentes à localização de indústrias no Município de Guarulhos, de 1920 a 1970. Não se trata de uma apresentação extensiva de todas as possibilidades de visualização que o sis-

15 Para isso, os nomes dos campos tiveram que ser normalizados (retirada de espaços em branco, acentos e cedilhas, e tamanho máximo de 10 caracteres).

16 Por intermédio da ajuda inestimável do técnico Guilherme Bagattini.

17 Foram disponibilizados os seguintes planos de informação: imagens de satélite, altimetria, bairros, geologia, hidrografia, hipsometria, mananciais, microbacias, morfologia, divisão da RMSP, arruamento, solos, termal, uso do solo e zona de amortecimento da Cantareira. tema oferece, mas de uma amostragem criteriosa que dê ideia das potencialidades ali embutidas. A exploração otimizada das funcionalidades de um SIG só pode se dar no próprio ambiente computacional que o abriga, no caso aqui o conjunto de arquivos do projeto organizados pelo software gvSIG.

Usando o plano de arruamento como plano de base, cada fábrica pode ser indicada com um ponto vermelho (fig. 1). Outra opção de visualização permite incorporar os nomes das ruas e das fábricas (fig. 2). Além disso um botão permite o obtenção de informações de cada fábrica, a partir do registro correspondente na tabela associada (fig. 3).

Todas as fábricas podem ser visualizadas simultaneamente agrupadas por décadas de fundação, com a simbologia respectiva (fig. 4), ou ainda podem ser produzidas legendas específicas, com visualização exclusiva, como, no exemplo, a referente apenas às fábricas da década de 60 ou a referente apenas às fábricas da década de 20 (fig. 5).

As décadas podem também ser alimentadas como planos de informação independentes. Essa alternativa tem a vantagem de permitir "ligar" ou "desligar" cada um dos planos separadamente, facilitando o reconhecimento de padrões de transformação ao longo do tempo como demonstrado nas figuras 6, 7, 8, 9 e 10 .

Por fim, segue um exemplo de visualização de mapa temático destinada à impressão (fig. 11)

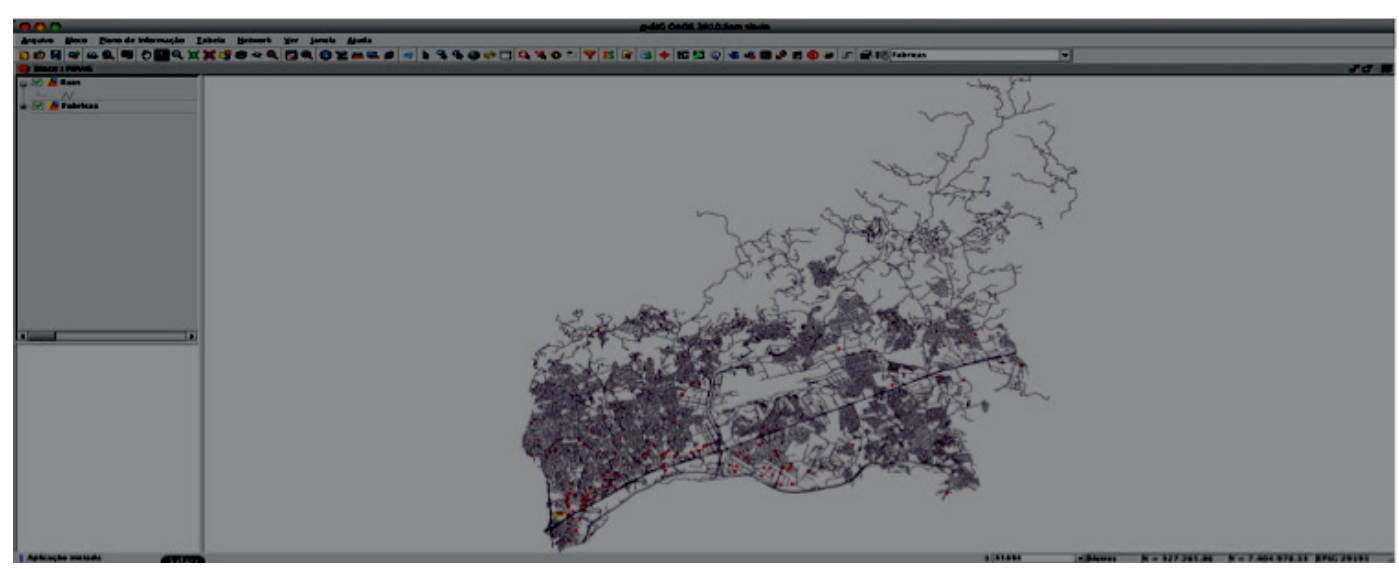

Fig. 1. Plano de arruamento com indicação individual de cada fábrica. 
Mapeamento SIG na Pesquisa e Inventário do Patrimônio Arqueológico de Guarulhos (PIPAG)

R. Museu Arq. Etn., 26: 84-94, 2016

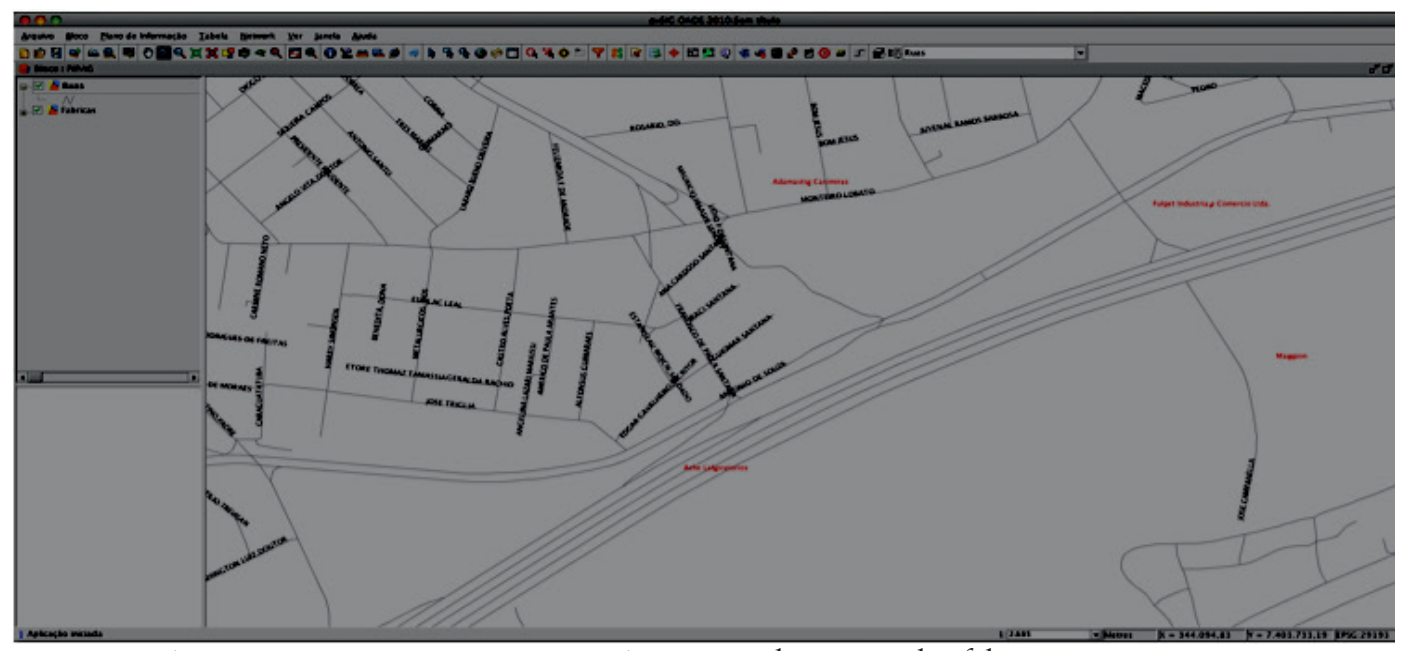

Fig. 2. Visualização em zoom com encorporação dos nomes das ruas e das fábricas.

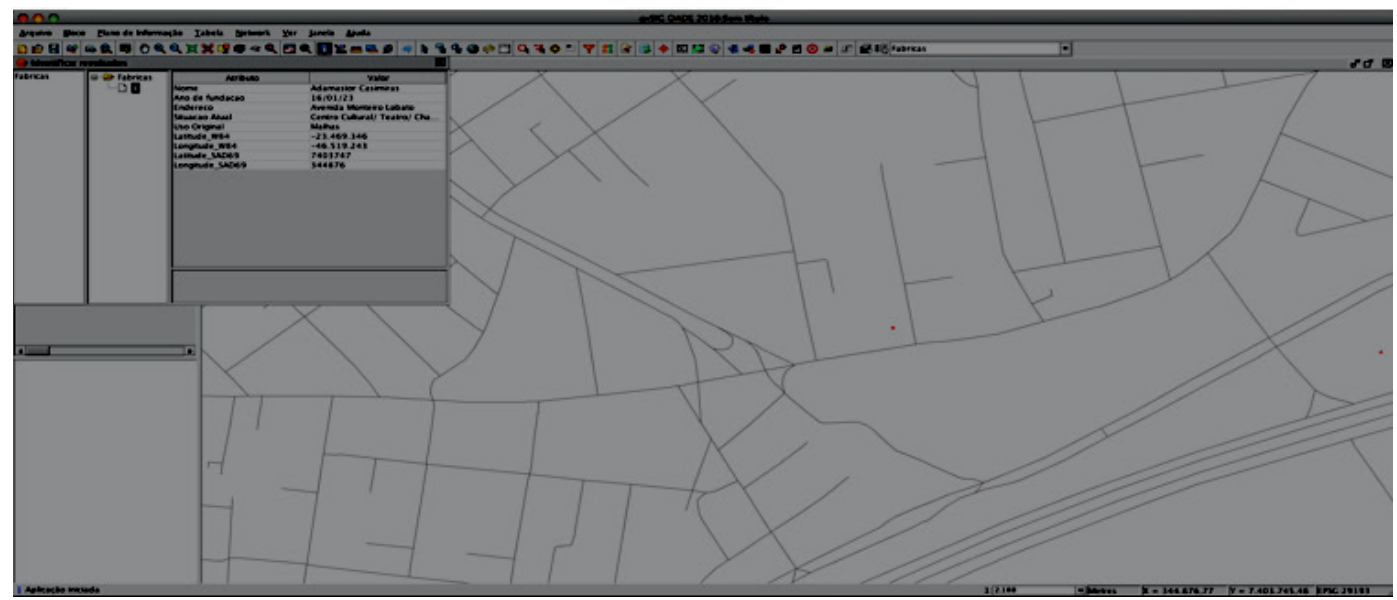

Fig. 3. Visualização das informações da fábrica.

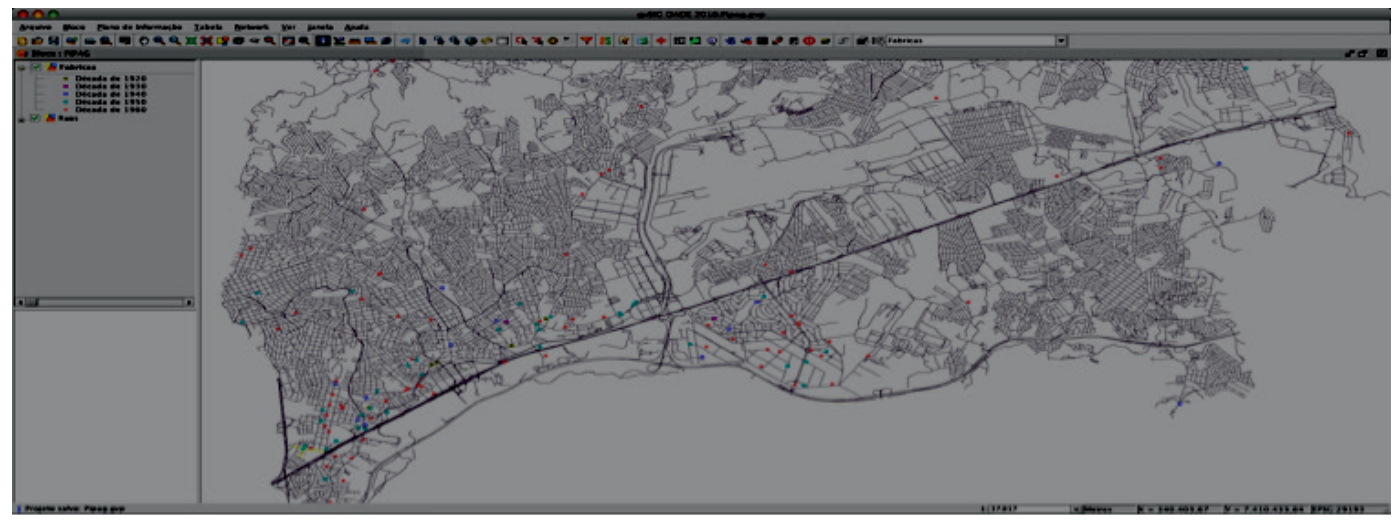

Fig. 4. Visualização da totalidade das fábricas com legenda de separação por década. 


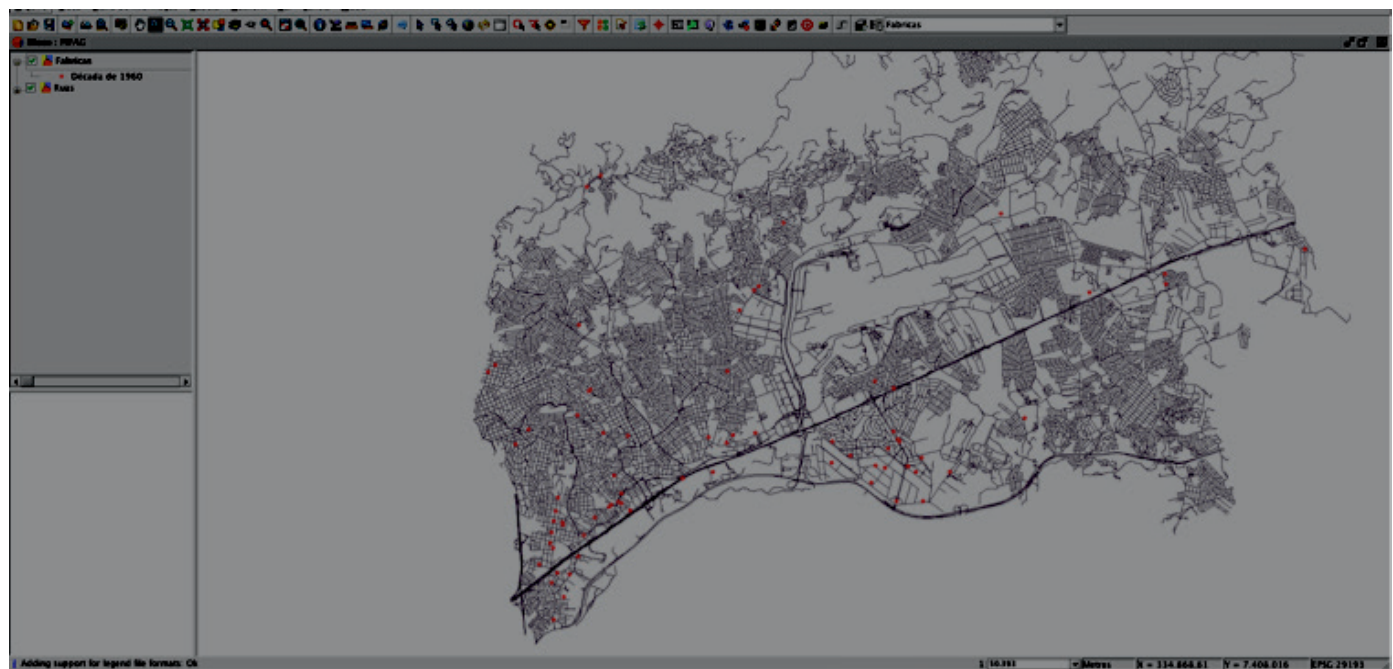

Fig. 5. Visualização apenas das fábricas da década de 60 .

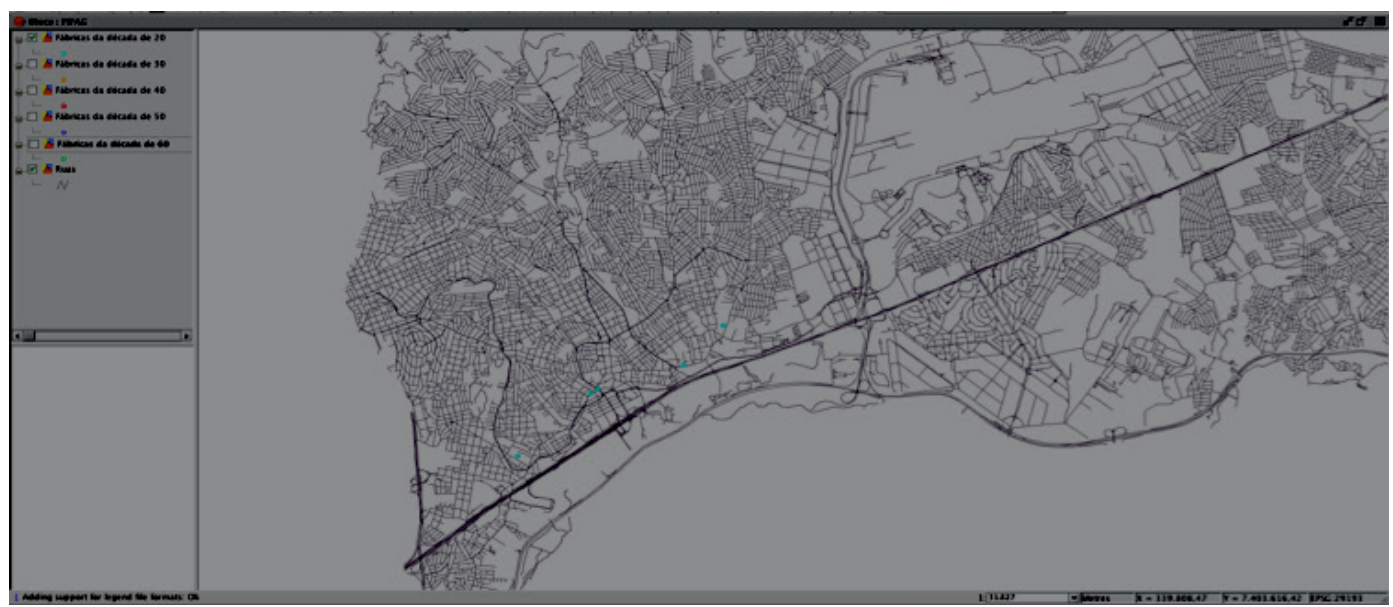

Fig. 6. Fábricas da década de 20.

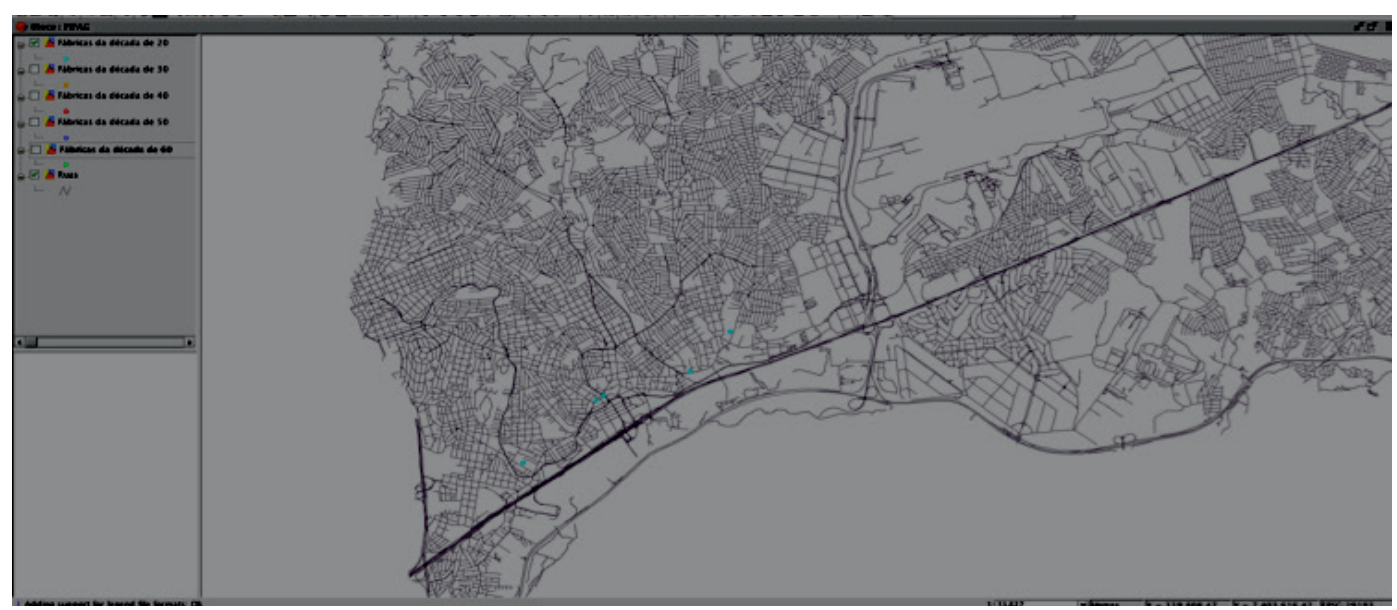

Fig. 7. Fábricas das décadas de 20 e 30 
Mapeamento SIG na Pesquisa e Inventário do Patrimônio Arqueológico de Guarulhos (PIPAG)

R. Museu Arq. Etn., 26: 84-94, 2016

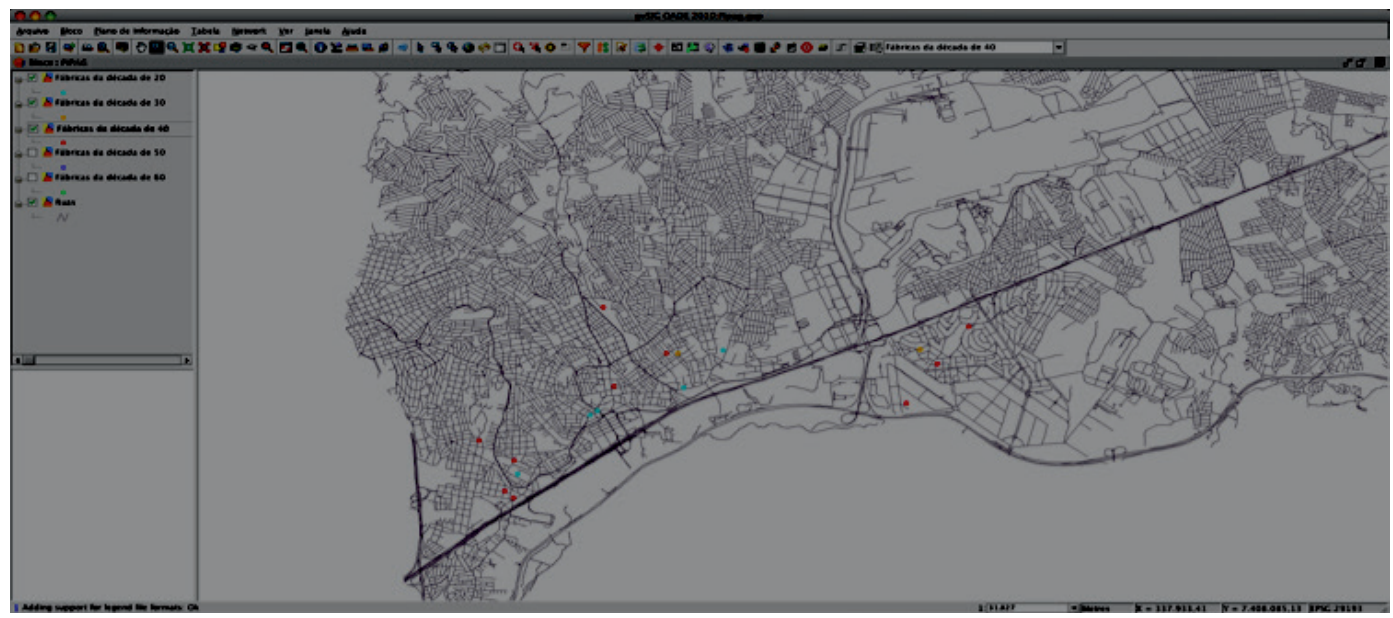

Fig. 8. Fábricas das décadas de 20, 30 e 40.

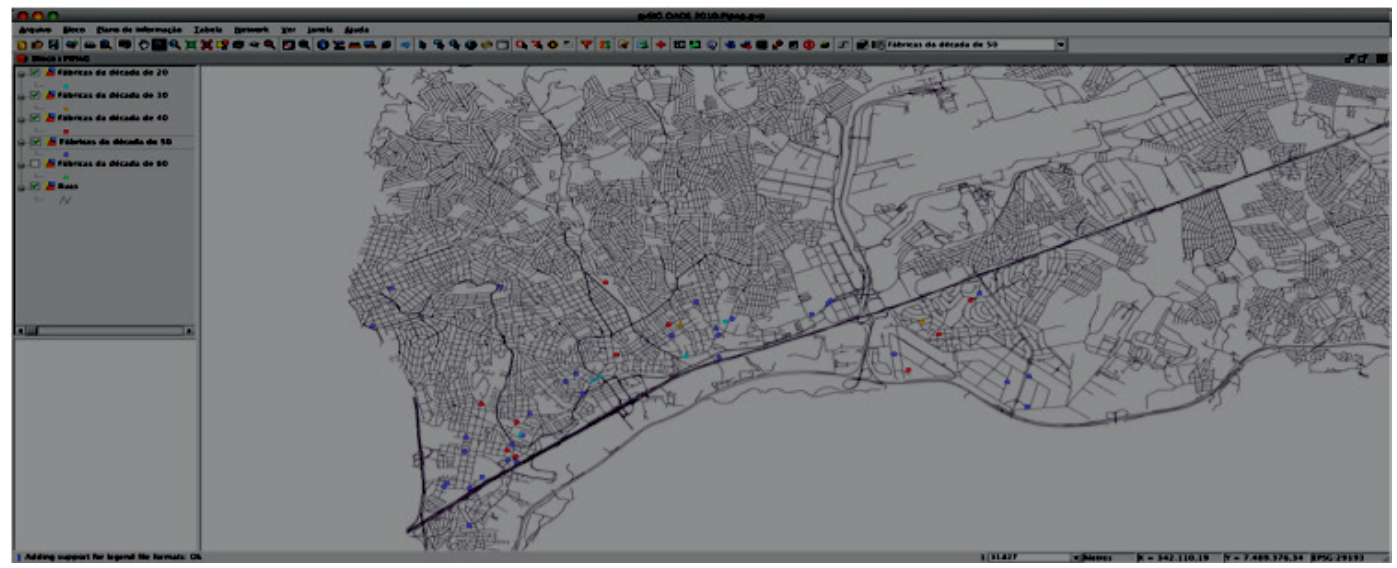

Fig. 9. Fábricas das décadas de 20, 30, 40 e 50;

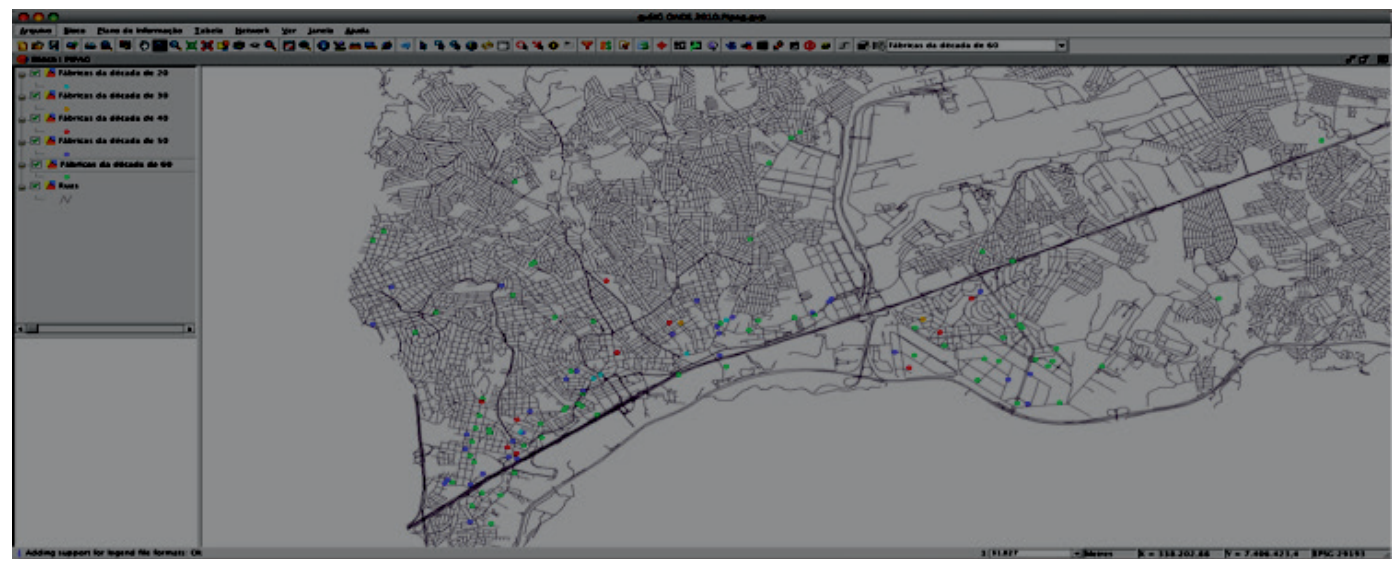

Fig. 10. Fábricas das décadas de 20, 30, 40, 50 e 60. 


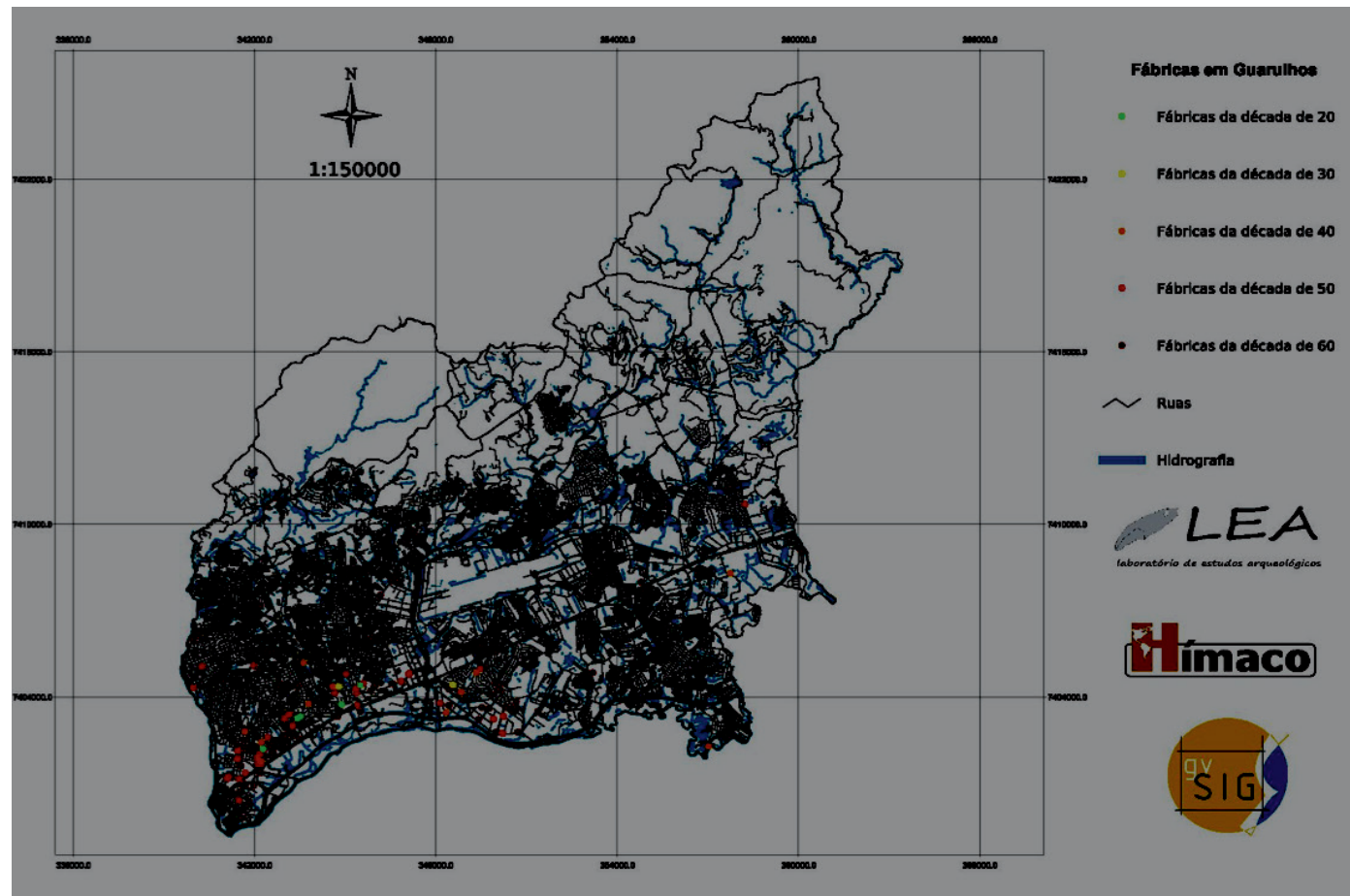

Fig. 11. Mapa para impressão

\section{Conclusão}

A metodologia aqui resumida exemplifica muito bem a conveniência da tecnologia escolhida, o SIG, para dar conta dos objetivos do projeto. Suas funcionalidades permitem a integração, em um mesmo ambiente computacional, de dados, fontes e informações de diversas origens e tipologias diferentes. No caso exemplificado, do mapeamento histórico das indústrias em Guarulhos, a pesquisa realizada previamente pela equipe do PET-História/Unifesp pode ser adaptada e articulada à base cartográfica atual da cidade, por sua vez disponibilizada pela Prefeitura daquele município. Toda a produção cartográfica do projeto foi realizada basicamente dessa forma, transformando os mapas resultantes em sínteses imagéticas de variados e polissêmicos levantamentos documentais dos pesquisadores do projeto, com todos os ganhos epistemológicos e também alguns riscos de simplificação que toda síntese implica. A equipe do projeto procurou ter a consciência sistemática tanto daqueles, como destes.
As principais funcionalidades técnicas que dão aos SIGs essa identidade metodológica são: a articulação entre as feições espaciais e respectivas informações alfa-numéricas organizadas em bancos de dados; e o processo de georreferenciamento. A primeira permite que muitos mapas temáticos possam ser produzidos a partir do manuseio do banco de dados, ao se escolher dentre as informações ali organizadas aquelas que se pretende sejam "traduzidas espacialmente". Já a segunda, também chamada de referenciamento geográfico, associa o espaço representado nos mapas às suas coordenadas no mundo real, o que, por sua vez, possibilita que as feições espaciais que ali se queira representar guardem as corretas relações topológicas entre si. Essas características técnicas é que diferenciam os SIGs dos softwares tradicionais de tratamento de imagem e de estruturação de lay-outs, ainda que esses possam ser utilizados como tecnologia auxiliar para melhorar a qualidade estética dos produtos finais.

O projeto em questão, com uma equipe interdisciplinar de pesquisadores que se de- 
dicou a levantamentos documentais os mais diversos, pode fazer uso do SIG enquanto a metodologia que atendesse a necessidade de produzir representações espaciais que refletissem minimamente a complexidade envolvida. No entanto, deve-se registrar que muitas das dificuldades inerentes ao uso de SIG em investigações históricas se fizeram presentes também nesse trabalho. Isso se deu particularmente na definição mais precisa da localização de muitos dos eventos estudados. Como discutido antes, há ainda uma persistente incompatibilidade entre a demanda por exatidão da tecnologia e o mundo impreciso da documentação histórica. Esse é o desafio mais importante que se colocam os historiadores que perseveram no uso dos SIG em seus trabalhos. Para tanto, estes não poderão prescindir de alguma criatividade, por exemplo no avanço do desenvolvimento de uma simbologia da imprecisão, e também de uma maior interlocução com os desenvolvedores da tecnologia, que apenas agora começam a ser pressionados por demandas dos pesquisadores das humanidades. Aqui reside uma vantagem adicional da utilização das tecnologias livres e de código aberto, muito mais sensíveis às necessidades dos usuários, que, diga-se, podem ser também eles mesmos desenvolvedores.

De uma forma geral, o mapeamento produzido no âmbito do Pipag é emblemático da crescente relação entre os arqueólogos e historiadores e as novas tecnologias, com todas as oportunidades e os desafios que ela traz. Além de atender às demandas de espacialização do projeto, tem-se a pretensão de que essa experiência possa de alguma maneira colaborar, ainda que modestamente, na discussão mais geral da afirmação do uso dos SIGs entre os historiadores, e de seu impacto na produção acadêmica contemporânea.

FERLA, L.; OYAKAWA, K.O.; DINIZ, J.A.; FARIAS, O.G.C. GIS Mapping in the Research and Inventory of Guarulhos's Archaeological Heritage (PIPAG). R. Museu Arq. Etn., 26: 84-94, 2016.

Abstract: The archaeological heritage mapping performed by the PIPAG Project used digital geotechnologies, more specifically the Geographic Information System (GIS). This article aims to discuss the chosen methodology, but not without first contextualizing it in terms of the impact, challenge and opportunities it represents considering the growing presence of these technologies in the historian routine. The account of our experience does not only exemplify the appropriateness of this technology for research spatialization in terms of the PIPAG, but also emphasizes its capacity to develop it in a widely synergic manner, as it allows the articulation among various initiatives and other participating research projects.

Keywords: digital humanities; geotechnologies; historical GIS; Guarulhos history. 


\section{Referências Bibliográficas}

Aronoff, S. 1995. Geographic information systems: a management perspective. Ottawa: WDL Publications.

Gregory, I.; Ell, P. 2007. Historical GIS: Technologies, methodologies and scholarship. Cambridge: Cambridge University Press.

Guest Editorial. 2004. "GRASS as Open Source Free Software GIS: Accomplishments and Perspectives". Transactions in GIS, 8 (2): $145-54$.

Ell, P.S.; Gregory, I.N. 2001. History and Computing, v. 13 (1).

Knowles, A. (Ed.). 2008. Placing history: how maps, spatial data, and GIS are changing historical scholarship. Redlands: Esri Press.
Plens, C.R. 2011. Pesquisa e Inventário do Patrimônio Arqueológico de Guarulhos. Projeto de Pesquisa.

Siebert, L. 2000. "Using GIS to document, visualize, and interpret Tokyo's Spatial History”. Social Science History, 24 (3): 537-74.

Knowles, A.K. 2000. Social Science History, v. 24 (3).

Páginas da Internet consultadas:

- http://www.informatik.uni-trier.de/ ley/db/journals/tgis/tgis8.html. Acesso em: 12 abr. 2015.

- www.gvsig.org. Acesso em: 12 abr. 2015.

- www.unifesp.br/himaco. Acesso em: 12 abr. 2015.

- http://maps.google.com.br/. Acesso em: 12 abr. 2015.

- http://splink.cria.org.br/conversor. Acesso em: 12 abr. 2015. 